\title{
The cost and management of different types of clinical mastitis in dairy cows estimated by dynamic programming
}

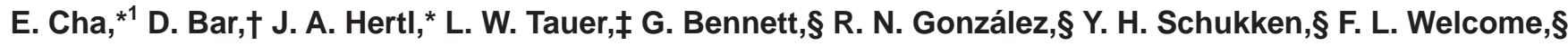 \\ and Y. T. Gröhn* \\ *Section of Epidemiology, Department of Population Medicine and Diagnostic Sciences, College of Veterinary Medicine, Cornell University, \\ Ithaca, NY 14853 \\ †SCR Engineers Ltd., 6 Haomanut St., Poleg, Industrial Zone, Netanya 42504, Israel \\ ¥Charles H. Dyson School of Applied Economics and Management, College of Agriculture and Life Sciences, and \\ $\S$ Quality Milk Production Services, Department of Population Medicine and Diagnostic Sciences, College of Veterinary Medicine, \\ Cornell University, Ithaca, NY 14853
}

\begin{abstract}
The objective of this study was to estimate the cost of 3 different types of clinical mastitis (CM) (caused by gram-positive bacteria, gram-negative bacteria, and other organisms) at the individual cow level and thereby identify the economically optimal management decision for each type of mastitis. We made modifications to an existing dynamic optimization and simulation model, studying the effects of various factors (incidence of CM, milk loss, pregnancy rate, and treatment cost) on the cost of different types of CM. The average costs per case (US\$) of gram-positive, gram-negative, and other CM were $\$ 133.73, \$ 211.03$, and $\$ 95.31$, respectively. This model provided a more informed decision-making process in CM management for optimal economic profitability and determined that $93.1 \%$ of gram-positive CM cases, $93.1 \%$ of gram-negative CM cases, and $94.6 \%$ of other CM cases should be treated. The main contributor to the total cost per case was treatment cost for gram-positive CM (51.5\% of the total cost per case), milk loss for gram-negative CM (72.4\%), and treatment cost for other CM (49.2\%). The model affords versatility as it allows for parameters such as production costs, economic values, and disease frequencies to be altered. Therefore, cost estimates are the direct outcome of the farm-specific parameters entered into the model. Thus, this model can provide farmers economically optimal guidelines specific to their individual cows suffering from different types of CM.
\end{abstract}

Key words: mastitis, gram-positive, gram-negative, dynamic programming

Received December 22, 2010.

Accepted May 24, 2011.

${ }^{1}$ Corresponding author: elvacha@gmail.com

\section{INTRODUCTION}

Mastitis reduces dairy farm profitability, with losses stemming from milk production decreases and discarded milk and costs of treatment and culling (Gröhn et al., 2005). The specific inflammatory response from a mastitis incident is dependent on the bacterial species involved (Bannerman, 2009). Depending on the pathogen involved, the effect may vary, so studies determining which pathogens have the greatest impact on cow health, production, and profitability are valuable (Gröhn et al., 2004).

Treatment for mastitis is the most common cause of antibacterial use on dairy farms. The possible health hazards posed by the presence of antibiotic residues and other drugs in milk are cause for public concern (Erskine et al., 2003), despite all bulk tanks being tested for antibiotics. Antibiotic use also raises questions of reduced animal welfare and biosecurity (Sørensen et al., 2010).

A fundamental component of mastitis control programs is the identification of pathogens in mastitis samples. For example, the ability to determine whether a cow is suffering from gram-positive or gram-negative CM would help determine the choice of antimicrobial therapy (Waage et al., 1994) and potentially reduce unnecessary use of antibiotics. Most pathogens that cause mastitis can be classified as gram-positive or gram-negative bacteria and determined by on-farm culturing, which is generally faster and more convenient than sending the milk sample to a commercial laboratory (Hertl et al., 2010). On-farm culture has an approximate 24-h turnaround time. The development of cow-side tests identifying whether a case of mastitis is gram-positive or gram-negative is ongoing (Waage et al., 1994; Yazdankhah et al., 2001). The objective of this study was to estimate the cost of different types of clinical mastitis (CM; caused by gram-positive bacteria, gram-negative bacteria, or other organisms) and to determine the optimal management decision, for each 
type of CM, of whether it is economically optimal for a cow to be (1) replaced with a heifer, (2) kept in the herd (and treated if she has CM) but not inseminated, or (3) kept (and treated if she has CM) and inseminated. We did this by modifying an existing dynamic programming model previously used to study $\mathrm{CM}$ and other diseases in dairy cows (Bar et al., 2008a; Cha et al., 2010).

\section{MATERIALS AND METHODS}

\section{Clinical Mastitis Categorization}

We classified CM into 3 categories: (1) CM due to gram-positive bacteria, (2) CM due to gram-negative bacteria, and (3) CM due to other organisms (hereafter, referred to as gram-positive CM, gram-negative $\mathrm{CM}$, and other $\mathrm{CM}$, respectively).

Species involved in gram-positive CM included Streptococcus spp., Staphylococcus aureus, and Staphylococcus spp. Species involved in gram-negative CM included Escherichia coli, Klebsiella spp., Citrobacter spp., and Enterobacter spp. Species involved in other CM included Arcanobacterium pyogenes, Mycoplasma spp., Corynebacterium bovis, Pseudomonas spp., and yeast.

\section{Optimization and Simulation Model}

Software. The model was built using the multilevel hierarchic Markov process (MLHMP) software as the application program interface (Kristensen, 2003). We modified an existing optimization and simulation model that was first developed to study the cost of generic CM in dairy cows, and then 3 different types of lameness in dairy cows (Bar et al., 2008a; Cha et al., 2010).

The Model. The model was constructed as a 3-level hierarchic Markov process comprising the founder (parent) level, containing state variables of permanent traits throughout the cow's life span, the child level divided into stages representing one whole lactation, and the grandchild level divided into stages of 1 mo during lactation. The possible actions in a given month of lactation that could occur at the final level were (1) replace the cow with a calving heifer, (2) keep the cow for another month without insemination and treat her if she has CM, or (3) keep the cow for another month, inseminate her, and treat her if she has CM (Bar et al., 2008a). Figure 1 is a schematic representation of the model used in the current study on CM. At the founder level, 5 milk yield categories $(\mathrm{kg})$ were modeled as $-5,-2.5,0,+2.5$, and +5 from the mean level of milk production per day; these represented the cow's genetic potential. At the child level, 8 possible whole-lactation stages were modeled. At the grandchild level, 20 lactation stages (mo) were modeled. In each stage, the cow was described by 1 level within each of the following states: 5 temporary (i.e., daily) milk yield levels, 9 pregnancy states $[0=$ open, $1-7$ $=1-7$ mo pregnant and milking, and $8=$ last 2 mo of pregnancy and dry (not milking)], 1 involuntarily culled state, and $13 \mathrm{CM}$ states. The $\mathrm{CM}$ states were defined as follows: $0=$ no $\mathrm{CM}$; $1=$ first occurrence of gram-positive CM (observed at the end of the stage enabling immediate culling with no loss to treatment or production); 2,3 , and $4=1,2,3$, and more months after the first case of gram-positive CM (this does not mean recurrence, but rather the time horizon since the first case of gram-positive $\mathrm{CM}$ ), respectively; $5=$ first occurrence of gram-negative $\mathrm{CM}$; and $9=$ other $\mathrm{CM}$ (with numbers from 6 to 8 and 10 to 12 corresponding to $1,2,3$, and more months after the first case of the CM type, respectively, and again, this does not mean recurrence, but rather time horizon since the first case of gram-negative or other CM, respectively).

In the case of recurrence, if a cow has recurrence of, for example, gram-positive CM, she will return to state 1 ; when she has recurrence of gram-negative $\mathrm{CM}$, she will return to state 5; and for other CM, she will return to state 9 .

The objective function maximized by the model was the discounting criterion (Kristensen, 2003), which maximizes the net present value (NPV) of the cow using a yearly interest rate of $8 \%$ (De Vries, 2006; Bar et al., 2008a; Federal Reserve Bank of Kansas City, 2011).

Optimization Technique. By combining the advantages of the 2 iteration methods used to solve the Markov process (namely, value iteration and policy iteration), a new notion of a hierarchic Markov process was developed by Kristensen $(1988,1991)$, which forms the basis of our dynamic program. This solution approach allows us to obtain solutions to large state-space problems, as described below (Kristensen, 1996).

Value iteration is performed to identify the decision that maximizes the total expected discounted rewards when the process starts from state $i$ and continues for $n$ stages before ending. Policy iteration involves choosing an arbitrary set of decision rules for each state at each stage and solving a set of simultaneous linear equations describing the expected future rewards of a process starting from state $i$ and running over an infinite number of stages until the same optimal decision is reached (Kristensen, 1996; Cha et al., 2010). Our model is structured in such a way that a cow can be replaced until time infinity; hence, at the founder (parent) level, we have an infinite time horizon. At the subprocess (child and grandchild) levels, however, we have a finite time horizon (i.e., the lifespan of a specific cow). 


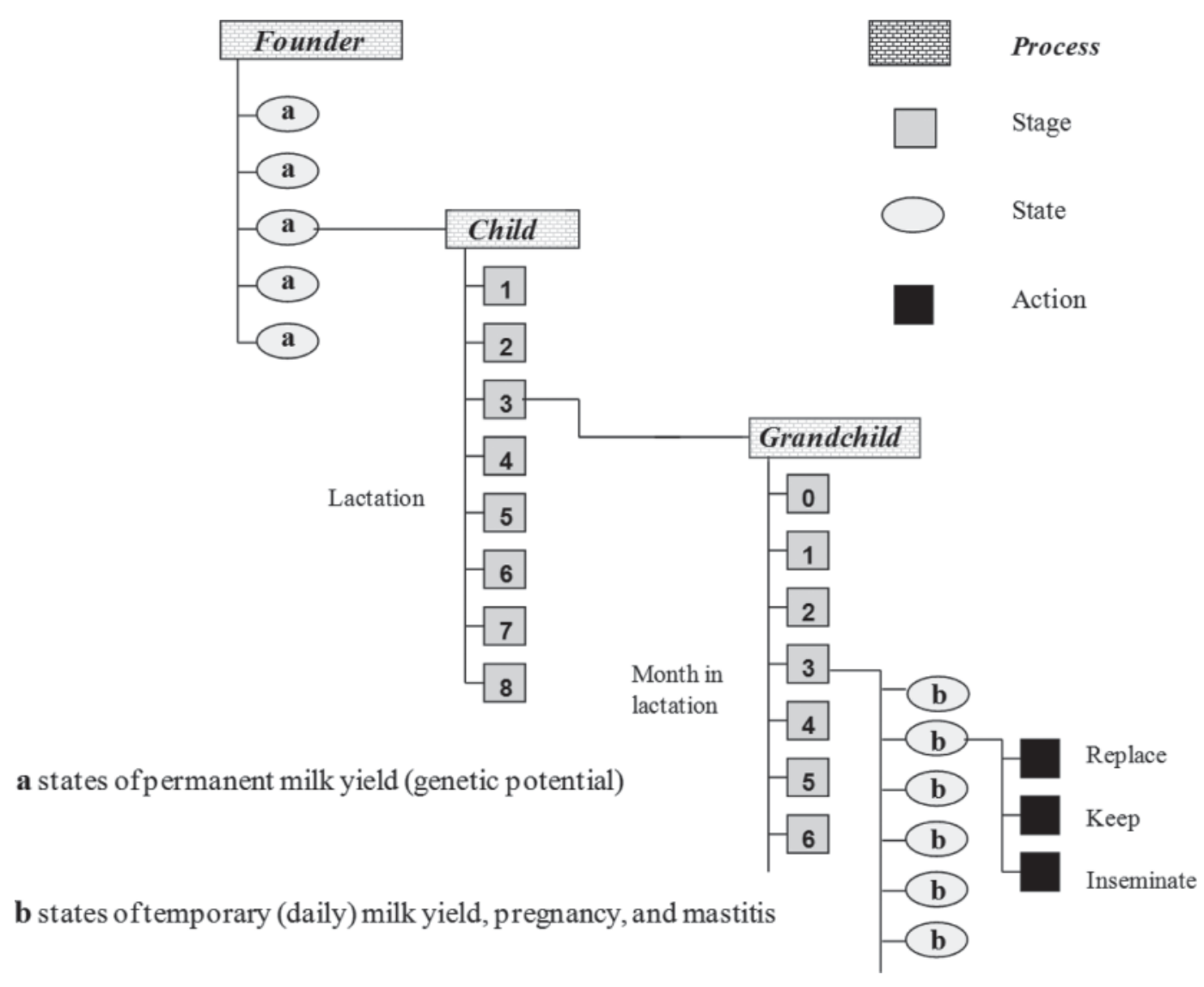

Figure 1. Schematic representation of the structure of the multilevel hierarchic Markov process optimization and simulation model to determine the average cost of clinical mastitis in dairy cows.

Kristensen $(1988,1991)$ combined the benefits of policy and value iteration, by applying value iteration to the subprocesses and using these results in the final step of the policy iteration method of the main process. Hence, in our model, at the founder level, we used policy iteration, and at the child and grandchild levels, value iteration (Figure 1). More details of the mathematics pertaining to this technique can be found in Cha et al. (2010).

\section{Model Parameters}

Model parameters were obtained from analyses of data from 7 dairy herds in New York State. These 7 herds were followed for approximately $4 \mathrm{yr}$ and contained 23,902 lactations in 14,208 cows.

Model parameters specific to the 3 different types of CM are given in Table 1. A decision to treat a cow with gram-positive CM was associated with a cost (US\$) of $\$ 73.50$. This cost was an estimated average from antibiotics (\$8), the decreased value of 5 days' worth of discarded milk from an average production cow $(\$ 20), 50 \%$ of cows receiving antiinflammatory drugs and fluid intravenously or per os $(\$ 15.50)$, labor $(\$ 20)$, and culturing $(\$ 10)$. A decision to treat a cow with gram-negative CM was associated with a cost of $\$ 35.50$. This cost was an estimated average from $50 \%$ of cows receiving antiinflammatory drugs and fluid intravenously or per os $(\$ 15.50)$, labor $(\$ 10)$, and culturing (\$10). The decision to treat a cow with other CM was associated with a cost of $\$ 49.50$. This was an estimated average from antibiotics (\$4), 50\% of cows receiving antiinflammatory medication and fluid intravenously or per os $(\$ 15.50)$, labor $(\$ 20)$, and culturing $(\$ 10)$; we assumed the discarded milk could be used in place of milk replacer for calves. Recognizing that the cost of treatment varies by farm (depending on drug administration, days of discarded milk due to drug use, and so on), a sensitivity analysis (described later below) of the cost of treatment was also performed.

Pregnancy risk was set to 0.21 per month. Odds ratios that would reduce the rate of conception for each type of CM were applicable only for the first month after the cow got $\mathrm{CM}$ (i.e., CM states 1, 5, and 9) and also if she got another case of the same type of $\mathrm{CM}$ (where she would return to state 1,5 , or 9 for a 
Table 1. Model parameters specific to 3 different types of clinical mastitis (CM)

\begin{tabular}{|c|c|c|c|c|}
\hline Parameter & Gram-positive CM & Gram-negative CM & Other CM & Reference \\
\hline \multicolumn{5}{|l|}{ Milk loss (kg/d) } \\
\hline First lactation, mo 1 after CM & 3.1 & 5.4 & 3.38 & \multirow{6}{*}{ Schukken et al., 2009} \\
\hline First lactation, mo 2 after CM & 2.25 & 3.35 & 2.03 & \\
\hline First lactation, following months & 1.0 & 2.6 & 1.7 & \\
\hline Second and third lactation, mo 1 after CM & 3.43 & 7.58 & 2.88 & \\
\hline Second and third lactation, mo 2 after CM & 1.48 & 3.65 & 1.23 & \\
\hline Second and third lactation, following months & 0.9 & 2.4 & 0.6 & \\
\hline Pregnancy rate adjusted by odds ratios & 0.76 & 0.65 & 0.84 & Hertl et al., 2010 \\
\hline Treatment cost $(\$)$ & 73.50 & 35.50 & 49.50 & See Materials and Methods \\
\hline \multicolumn{5}{|l|}{ Risk (\%) } \\
\hline \multicolumn{5}{|l|}{ First case } \\
\hline First lactation & $0.019,0.005,0.006,0.006^{1}$ & $0.008,0.006,0.005,0.005$ & $0.015,0.008,0.007,0.006$ & \multirow[t]{9}{*}{ See Materials and Methods } \\
\hline Second lactation & $0.017,0.01,0.013,0.01$ & $0.018,0.02,0.02,0.013$ & $0.022,0.015,0.016,0.013$ & \\
\hline Third lactation & $0.02,0.012,0.016,0.013$ & $0.024,0.026,0.027,0.017$ & $0.027,0.019,0.02,0.016$ & \\
\hline Fourth+ lactation & $0.026,0.013,0.02,0.016$ & $0.027,0.03,0.03,0.02$ & $0.032,0.023,0.023,0.02$ & \\
\hline \multicolumn{4}{|l|}{ Second case } & \\
\hline First lactation & $0.035,0.015,0.013,0.01$ & $0.03,0.02,0.015,0.01$ & $0.04,0.02,0.01,0.01$ & \\
\hline Second lactation & $0.042,0.03,0.024,0.02$ & $0.046,0.044,0.026,0.017$ & $0.065,0.048,0.035,0.031$ & \\
\hline Third lactation & $0.043,0.03,0.025,0.02$ & $0.054,0.052,0.044,0.021$ & $0.077,0.074,0.042,0.037$ & \\
\hline Fourth+ lactation & $0.039,0.03,0.023,0.02$ & $0.051,0.049,0.029,0.019$ & $0.075,0.056,0.041,0.037$ & \\
\hline Involuntary culling risk ${ }^{2}$ & $\begin{array}{l}0.006,0.01,0.02,0.03 \\
0.04,0.05,0.06,0.07\end{array}$ & $\begin{array}{l}0.024,0.4,0.08,0.12 \\
0.15,0.15,0.15,0.15\end{array}$ & $\begin{array}{l}0.006,0.01,0.02,0.03 \\
0.04,0.05,0.06,0.07\end{array}$ & $\begin{array}{l}\text { Bar et al., 2008a; } \\
\text { and unpublished data }\end{array}$ \\
\hline Mortality risk & & 0.02 and $0.04^{3}$ & & Gröhn et al., 2005 \\
\hline
\end{tabular}

을 ${ }^{1}$ According to mo $1,2,3$, and $4+$.

@ $\quad{ }^{2}$ Monthly involuntary culling risks for lactations 1 through 8.

${ }_{0}^{3}$ For primiparous and multiparous animals, respectively. 
recurrent case of gram-positive, gram-negative, or other $\mathrm{CM}$, respectively). If a cow contracted $\mathrm{CM}$, the probability of going into the pregnancy state the following month was multiplied by this formula: [pregnancy rate $\times$ conception odds ratio for type of $\mathrm{CM} /(1-$ pregnancy rate + pregnancy rate $\times$ conception odds ratio for type of $\mathrm{CM}$ )]. The voluntary waiting period was 60 $\mathrm{d}$, the maximum calving interval was $20 \mathrm{mo}$, and the involuntary culling risk at calving was $2 \%$.

The monthly risk estimates (first case and recurrent cases), by lactation and CM type, were obtained from generalized linear mixed models with a random herd effect. The monthly risks for repeated cases were an average of the monthly risks for the second and third $\mathrm{CM}$ occurrence. The monthly risk estimates for the second $\mathrm{CM}$ occurrence in multiparous cows meant the cow could have had any type of CM within the lactation (and no CM in the previous lactation). The monthly risk estimates for the third $\mathrm{CM}$ occurrence in multiparous cows referred to cows that had already experienced 2 cases of CM (of any type) within the lactation and without $\mathrm{CM}$ in the previous lactation.

The cost of a calving first-lactation animal was $\$ 1,600$, average monthly cow maintenance cost was $\$ 150$, and insemination cost/month of insemination was $\$ 20$. The average price for a calf born was $\$ 200$. The milk price was $\$ 0.31 / \mathrm{kg}$ and the feed cost $/ \mathrm{kg}$ of dry matter was $\$ 0.20$. The cull price for voluntarily culled cows was $\$ 0.74 / \mathrm{kg}$ of BW.

Other parameters and prices and costs were taken from Bar (2007), De Vries (2006), and Bar et al. (2008a). The milk yields, transition probabilities (the probabilities describing the different states a cow can transition to from one month to another), exit from the herd, and effects of CM are described in Bar et al. (2008a).

\section{Estimating CM Cost}

The average net returns per cow per year for a herd without CM were compared with the average net returns per cow per year for a herd with CM (by type), while keeping other parameters constant. Profit or loss was divided by $\mathrm{CM}$ incidence to generate the herd-average cost per case of CM. As the cost of CM was minimized under optimal treatment decisions, it is possible that these values differ from actual farm figures. The effects of milk loss, decreased fertility, and treatment cost on the average cost of a CM case were also determined by obtaining the NPV of the model with and without the CM type and effect in question, and then dividing by the incidence of CM.

The NPV is the current value of actions where the benefits and costs of the actions are calculated until the end of the time horizon. This is achieved by discounting the various benefits and costs by an annual interest rate over that period. An interest rate of $8 \%$ was used (De Vries, 2006; Bar et al., 2008a; Federal Reserve Bank of Kansas City, 2011). The discounting factor $(\beta)$ is equal to $\exp (-r)$ where $r=0.08$; that is, $\beta=0.92$. The retention payoff (RPO) value is the NPV of retaining a cow compared with the NPV of her replacement (Bar et al., 2008b); that is, $\mathrm{NPV}_{\text {retaining }}-\mathrm{NPV}_{\text {replacing. }}$.

\section{Exit from the Herd}

Exit from the herd could be due to 2 reasons: (1) voluntary culling based on what the model recommends or (2) involuntary culling. Involuntary culling can be due to euthanasia or cows sold for slaughter for reasons other than milk yield, pregnancy, or CM (i.e., reasons not determined directly from the model). The values used for the probability of involuntary culling are discussed in Bar et al. (2008a). As the probability of involuntary culling of gram-negative mastitic cows was approximately 4 times that of healthy cows, this was reflected in the monthly involuntary culling values used in our model for gram-negative CM (unpublished data). The mortality of gram-negative CM was simplified to be $2 \%$ and $4 \%$ for primiparous and multiparous animals, respectively (Gröhn et al., 2005).

\section{Sensitivity Analyses}

Given that economic values such as milk price, replacement cost, and treatment cost can vary from time to time and from farm to farm, a sensitivity analysis was performed to evaluate how an increase and decrease of $20 \%$ in each of these values individually affected the percentage of CM cases in the herd and the average cost per case. Further, we measured the effect of halving the incidence of all 3 different types of CM, and also the effect of increasing the pregnancy rate by $20 \%$ (from 0.21 to 0.25 ) to determine which of these 2 management measures has the most beneficial effect on the average cost per case of CM.

\section{RESULTS}

\section{The Cost of Different Types of CM}

The effects of each different type of CM on net return, incidence of CM, percentage of CM cases treated, average cost of $\mathrm{CM}$, and average cost per case are shown in Table 2 . The monetary values correspond to averaging over cow characteristics (e.g., parity, month of lactation). The average cost per case was greatest for gram-negative $\mathrm{CM}$ at $\$ 211.03[\$ 32.71 / 0.155$, where 
Table 2. The effects of different types of clinical mastitis (CM; gram-positive, gram-negative, other) on net return, $\mathrm{CM}$ cases, \% of $\mathrm{CM}$ cases treated, average cost of $\mathrm{CM}$, and average cost per case, following an optimal replacement policy (all costs in US\$)

\begin{tabular}{|c|c|c|c|c|c|}
\hline Item & $\begin{array}{l}\text { Net } \\
\text { return }\end{array}$ & $\begin{array}{c}\mathrm{CM} \\
\text { cases }^{2}\end{array}$ & $\begin{array}{l}\text { CM cases } \\
\text { treated }^{3}\end{array}$ & $\begin{array}{c}\text { Average } \\
\text { cost of CM }\end{array}$ & $\begin{array}{l}\text { Average cost } \\
\text { per case }^{4}\end{array}$ \\
\hline No $\mathrm{CM}^{5}$ & 426.05 & & & & \\
\hline $\mathrm{All}^{6}$ & 357.35 & 44.3 & 93.6 & 68.70 & 155.08 \\
\hline Gram-negative and other ${ }^{7}$ & 374.20 & & & & \\
\hline Only gram-positive ${ }^{8}$ & & 12.6 & 93.1 & 16.85 & 133.73 \\
\hline Gram-positive and other & 390.06 & & & & \\
\hline Only gram-negative & & 15.5 & 93.1 & 32.71 & 211.03 \\
\hline Gram-positive and gram-negative & 372.79 & & & & \\
\hline Only other & & 16.2 & 94.6 & 15.44 & 95.31 \\
\hline
\end{tabular}

${ }^{1}$ Net returns in US $\$$ per cow and year.

${ }^{2}$ Incidence of CM (cases per 100 cow-years).

${ }^{3}$ Percentage of treated CM cows per all CM cows.

${ }^{4}$ Average cost per CM case.

${ }^{5} \mathrm{CM}$ incidences set to 0 .

${ }^{6}$ All 3 types of CM.

${ }^{7}$ Incidences of gram-negative and other CM included only.

${ }^{8}$ Added effects of gram-positive CM only.

32.71 is the average cost $(\$ 390.06-\$ 357.35)$ and 0.155 is the incidence of gram-negative $\mathrm{CM}]$, followed by gram-positive CM at $\$ 133.73(\$ 16.85 / 0.126)$, and other CM at $\$ 95.31$ ( $\$ 15.44 / 0.162)$. The percentage of mastitic cows for which treatment was recommended, following an optimal replacement policy, was 93.1, 93.1, and $94.6 \%$ for gram-positive, gram-negative, and other $\mathrm{CM}$, respectively. For the remainder of cows, the recommended policy was to cull immediately.

\section{The Effects of Exogenous Factors on the Cost of Different Types of CM}

We quantified how penalties associated with each type of CM; that is, milk loss, decreased fertility, and treatment cost, contributed to the average cost per case of each type of CM. For gram-positive CM, the total cost (\$133.73) comprised mostly treatment cost ( $\$ 68.89 ; 51.5 \%$ of the total cost), followed by milk loss $(\$ 49.64 ; 37.1 \%)$ and decreased fertility $(\$ 15.20 ; 11.4 \%)$. For gram-negative CM, the total cost $(\$ 211.04)$ was primarily from milk loss $(\$ 152.76 ; 72.4 \%)$, followed by treatment cost $(\$ 32.74 ; 15.5 \%)$ and decreased fertility $(\$ 25.54 ; 12.1 \%)$. For other $\mathrm{CM}$, the same trend was seen as for gram-positive CM; that is, the treatment cost $(\$ 46.86 ; 49.2 \%)$ contributed most to the total cost (\$95.30), followed by milk loss $(\$ 38.64 ; 40.5 \%)$ and decreased fertility $(\$ 9.80 ; 10.3 \%)$.

We increased and decreased the milk price by $20 \%$ to observe how sensitive the average cost/case was to milk prices for each type of CM (Table 3). The average cost/ case of all CM increased by $11.7 \%$ (from $\$ 155.08$ to $\$ 173.23$ ) when we increased the milk price by $20 \%$, and decreased by $11.1 \%$ (from $\$ 155.08$ to $\$ 137.91$ ) when we decreased the milk price by $20 \%$. Gram-negative CM was most sensitive to these changes; the average cost per case increased by $14 \%$ (from $\$ 211.03$ to $\$ 240.63$ ) and decreased $13.1 \%$ (from $\$ 211.03$ to $\$ 183.37$ ) when milk price was increased and decreased by $20 \%$, respectively.

When we increased and decreased the replacement cost by $20 \%$, the average cost/case of CM increased by $5.3 \%$ (from $\$ 155.08$ to $\$ 163.23$ ) and decreased by $4.1 \%$ (from $\$ 155.08$ to $\$ 148.67$ ), respectively (Table 3 ). Gram-negative CM was most sensitive to these changes; the average cost/case increased by $6.7 \%$ (from $\$ 211.03$ to $\$ 225.15$ ) and decreased by $5.2 \%$ (from $\$ 211.03$ to $\$ 200.06$ ) when replacement cost was increased and decreased by $20 \%$, respectively.

When we increased and decreased the treatment cost by $20 \%$, the greatest change in cost/case was seen for gram-positive CM (increase of $10.4 \%$, from $\$ 133.73$ to $\$ 147.60$, and decrease of $10.2 \%$, from $\$ 133.73$ to $\$ 120.13$, respectively), followed by other CM (increase of $9.2 \%$, from $\$ 95.31$ to $\$ 104.10$, and decrease of $8.9 \%$ from $\$ 95.31$ to $\$ 86.84$ ), and gram-negative CM (increase of $3.6 \%$, from $\$ 211.03$ to $\$ 218.57$, and decrease of $3.4 \%$ from $\$ 211.03$ to $\$ 203.96$; Table 3).

The average cost per case increased when the incidence of all different types of CM was halved. The greatest increase was in the other CM category (from $\$ 95.31$ to $\$ 98.47$, a $3.3 \%$ increase; Table 3$)$.

When pregnancy rate was increased by $20 \%$, the average cost per case decreased. Of the 3 categories of $\mathrm{CM}$, the largest decrease was seen in the other category (from $\$ 95.31$ to $\$ 92.70$, a $2.7 \%$ decrease; Table 3). 
Table 3. Effects of increasing and decreasing milk price replacement cost and treatment cost by $20 \%$, halving the incidence of all 3 types of clinical mastitis (CM), and increasing C) pregnancy rate by $20 \%$ on CM cases and the average cost/case for all CM and for each type of $\mathrm{CM}$

\begin{tabular}{|c|c|c|c|c|c|c|c|c|}
\hline \multirow[b]{2}{*}{ Scenario } & \multicolumn{2}{|c|}{ All types of CM } & \multicolumn{2}{|c|}{ Gram-positive only } & \multicolumn{2}{|c|}{ Gram-negative only } & \multicolumn{2}{|r|}{ Other } \\
\hline & $\begin{array}{c}\mathrm{CM} \\
\text { cases }^{1}\end{array}$ & $\begin{array}{c}\text { Average } \\
\text { cost/case }(\$)\end{array}$ & $\begin{array}{l}\mathrm{CM} \\
\text { cases }\end{array}$ & $\begin{array}{c}\text { Average } \\
\text { cost/case }(\$)\end{array}$ & $\begin{array}{l}\mathrm{CM} \\
\text { cases }\end{array}$ & $\begin{array}{c}\text { Average } \\
\text { cost/case }(\$)\end{array}$ & $\begin{array}{l}\mathrm{CM} \\
\text { cases }\end{array}$ & $\begin{array}{c}\text { Average } \\
\text { cost/CM case }(\$)\end{array}$ \\
\hline Milk price $+20 \%$ & 43.5 & 173.23 & 12.4 & 145.36 & 15.1 & 240.63 & 15.9 & 105.08 \\
\hline Milk price $-20 \%$ & 45.3 & 137.91 & 12.8 & 123.49 & 15.9 & 183.37 & 15.9 & 90.10 \\
\hline Replacement cost $+20 \%$ & 45.1 & 163.23 & 12.8 & 138.70 & 15.8 & 225.15 & 16.5 & 99.05 \\
\hline Replacement cost $-20 \%$ & 43 & 148.67 & 12.3 & 130.58 & 15 & 200.06 & 15.8 & 93.13 \\
\hline Treatment cost $+20 \%$ & 44.2 & 164.97 & 12.6 & 147.60 & 15.5 & 218.57 & 16.2 & 104.10 \\
\hline Treatment cost $-20 \%$ & 44.3 & 145.59 & 12.6 & 120.13 & 15.5 & 203.96 & 16.2 & 86.84 \\
\hline Halving incidence of all 3 types of CM & 23 & 158.17 & 6.5 & 141.42 & 8 & 218.93 & 8.5 & 100.41 \\
\hline Increasing pregnancy rate by $20 \%$ & 45.7 & 150.35 & 12.9 & 131.55 & 16.1 & 205.90 & 16.7 & 92.70 \\
\hline
\end{tabular}

${ }^{1}$ Incidence of CM (cases per 100 cow-years).

Table 4. Average costs (in US\$) of 3 types of clinical mastitis (CM) in cows with different levels (low, average, high) of permanent (genetically determined) milk yield potential 4 mo after calving, obtained by the insemination and replacement optimization model $^{1}$

\begin{tabular}{|c|c|c|c|c|c|c|c|c|c|c|c|c|c|c|c|c|c|c|}
\hline \multirow[b]{4}{*}{ Lactation } & \multicolumn{18}{|c|}{ Permanent milk yield potential } \\
\hline & \multicolumn{6}{|c|}{ Low } & \multicolumn{6}{|c|}{ Average } & \multicolumn{6}{|c|}{ High } \\
\hline & \multicolumn{3}{|c|}{ Open } & \multicolumn{3}{|c|}{ Pregnant } & \multicolumn{3}{|c|}{ Open } & \multicolumn{3}{|c|}{ Pregnant } & \multicolumn{3}{|c|}{ Open } & \multicolumn{3}{|c|}{ Pregnant } \\
\hline & GP & GN & $\mathrm{O}$ & GP & GN & $\mathrm{O}$ & GP & GN & $\mathrm{O}$ & GP & GN & $\mathrm{O}$ & GP & GN & $\mathrm{O}$ & GP & GN & $\mathrm{O}$ \\
\hline 1 & 136 & 150 & 126 & 125 & 140 & 115 & 167 & 216 & 154 & 125 & 154 & 115 & 152 & 245 & 160 & 125 & 171 & 115 \\
\hline 2 & 131 & 150 & 96 & 123 & 147 & 90 & 178 & 269 & 139 & 124 & 165 & 91 & 206 & 352 & 164 & 124 & 189 & 91 \\
\hline 3 & 116 & 136 & 86 & 121 & 151 & 92 & 156 & 240 & 127 & 122 & 180 & 93 & 176 & 323 & 148 & 124 & 219 & 95 \\
\hline 6 & 105 & 117 & 76 & 102 & 112 & 74 & 114 & 149 & 84 & 115 & 159 & 86 & 137 & 229 & 109 & 116 & 196 & 85 \\
\hline
\end{tabular}

${ }^{1} \mathrm{GP}=$ gram-positive $\mathrm{CM} ; \mathrm{GN}=$ gram-negative $\mathrm{CM}$; and $\mathrm{O}=$ other $\mathrm{CM}$ 


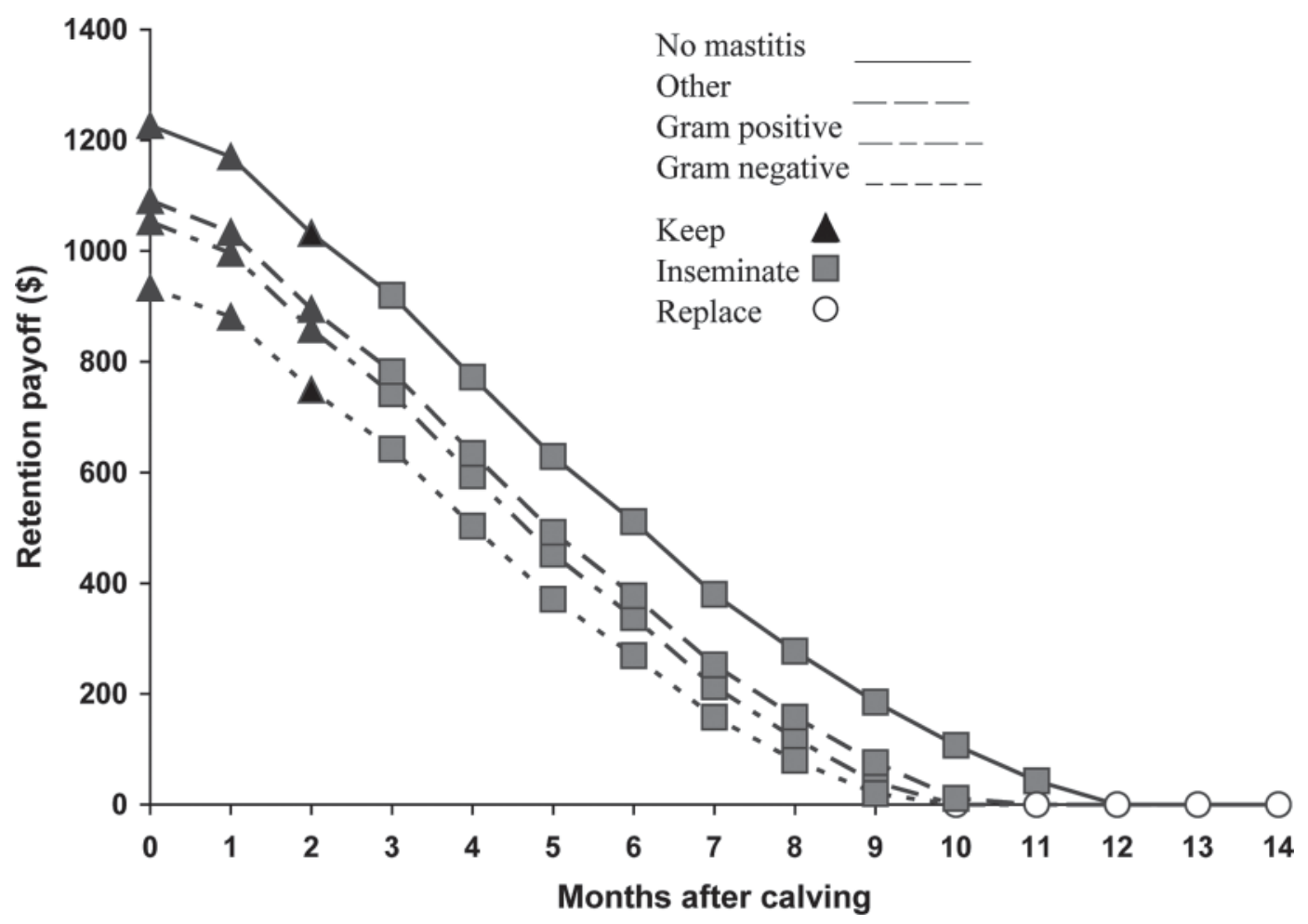

Figure 2. Retention payoffs under an optimal policy for hypothetically open (non-pregnant) cows free of clinical mastitis (CM) and with different types of CM, specific to a second-lactation cow with average milk yield per 305-d lactation.

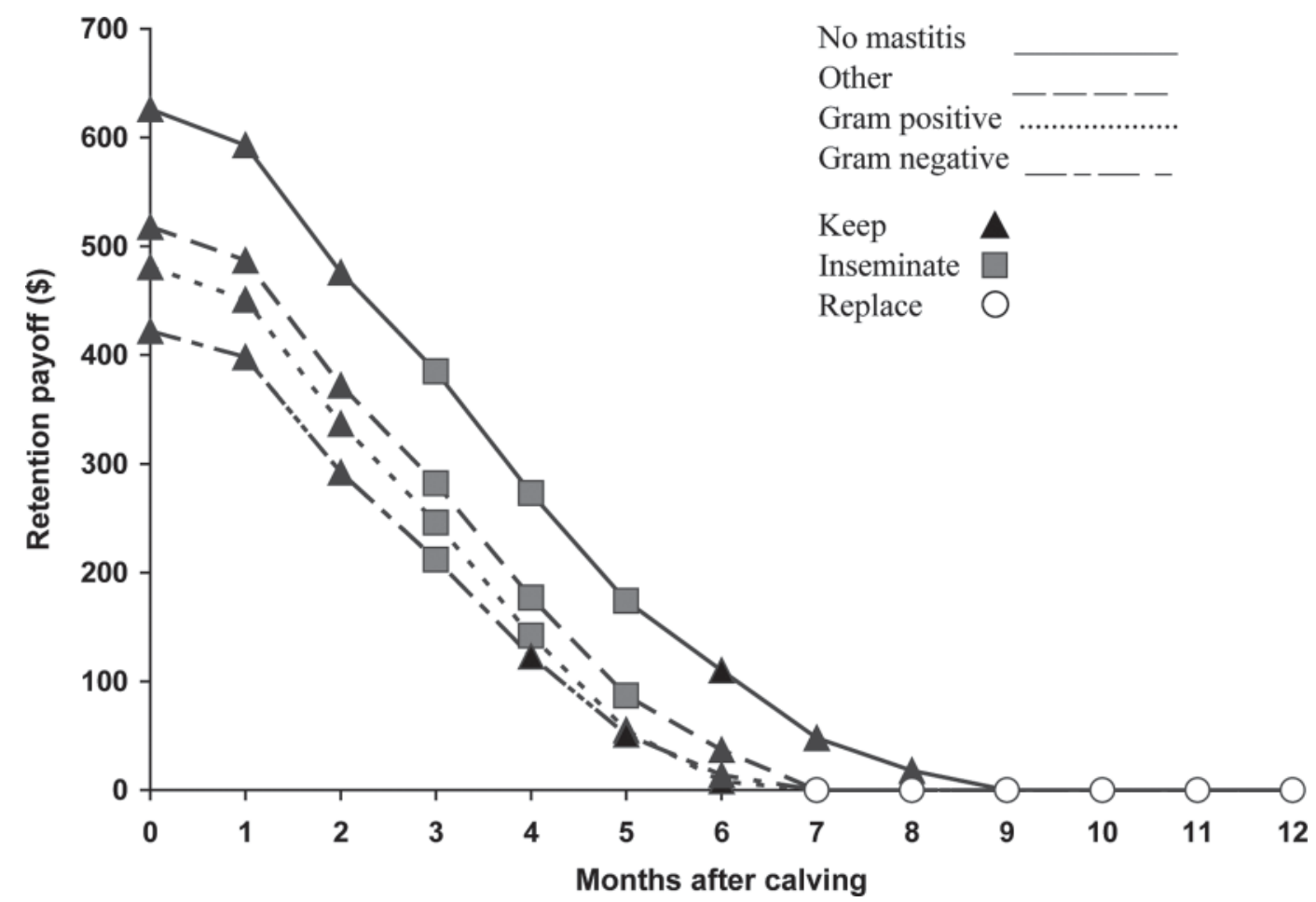

Figure 3. Retention payoffs under an optimal policy for hypothetically open (non-pregnant), second-lactation cows, with permanent milk yield of 1,500 kg per 305-d lactation less than the average in the herd, free of clinical mastitis (CM), and with different types of CM (note: grampositive and gram-negative CM graphs overlap from month 5). 


\section{RPO of Open Healthy and Mastitic Cows}

Our economic model calculates the RPO for cows, dependent on their individual characteristics. Figures 2 and 3 show hypothetical examples of RPO under an optimal policy for cows free of $\mathrm{CM}$ and with different types of CM, specific to an open (non-pregnant), second-lactation cow with average milk yield per 305-d lactation, and with permanent milk yield of $1,500 \mathrm{~kg}$ per 305-d lactation less than the average in the herd, respectively. The optimal policy recommended by the model (keep but not inseminate, keep and inseminate, or replace) is also illustrated by the symbols on the graph.

In Figure 2, the RPO (US\$) of cows at calving was $\$ 1,227, \$ 1,091, \$ 1,053$, and $\$ 933$ for no CM, other CM, gram-positive $\mathrm{CM}$, and gram-negative $\mathrm{CM}$, respectively. The average cost at calving was calculated by subtracting the RPO for the different types of CM from the RPO for no CM. The average cost at calving was $\$ 136$ (\$1,227 - \$1,091), \$174 (\$1,227 - \$1,053), and $\$ 294$ ( $\$ 1,227$ - \$933) for other CM, gram-positive CM, and gram-negative CM, respectively. When the RPO is negative, it is more profitable to cull the cow than to keep her. This was observed at mo 12 for no CM, mo 11 for other CM, and mo 10 for gram-positive and gramnegative CM. Figure 2 illustrates the recommended policy until mo 14; the model recommended that cows in mo 14 and onward be replaced.

In Figure 3, it can be seen that the culling recommendation has shifted forward; that is, culling was recommended at mo 9 for a cow without CM and at mo 7 for cows with gram-positive, gram-negative, and other $\mathrm{CM}$. The RPO of these cows at calving was $\$ 626, \$ 518$, $\$ 481$, and $\$ 422$, for no CM, other CM, gram-positive, and gram-negative CM, respectively. Therefore, the average cost at calving was $\$ 108(\$ 626-\$ 518), \$ 145$ $(\$ 626-\$ 481)$, and $\$ 204(\$ 626-\$ 422)$ for other CM, gram-positive, and gram-negative CM, respectively. Figure 3 illustrates the recommended policy until mo 12; the model recommended that cows in mo 12 and onward be replaced.

\section{Endogenous Factors Affecting the Cost of CM}

Tables 4 and 5 provide a cross-sectional view of Figures 2 and 3 at 4 and 8 mo after calving, respectively (but with more information than the figures; Tables 4 and 5 also include cows of high permanent milk yield potential and pregnant cows).

The cost of CM is dependent on endogenous factors; that is, permanent (genetic) milk yield potential, pregnancy status, and lactation (Tables 4 and 5). The general trends are discussed below.
For a cow 4 mo after calving (Table 4), we found that the average cost of $\mathrm{CM}$ was greater in open cows compared with pregnant cows. In addition, the average cost of CM was greater in younger cows compared with older cows.

The average cost was greatest for gram-negative CM, followed by gram-positive CM, and other CM, for each permanent milk yield potential and pregnancy status combination. Moreover, the cost was greatest for highyielding cows, followed by average- and low-yielding cows.

At 8 mo after calving (Table 5), the average cost was generally greater for cows suffering from gram-negative $\mathrm{CM}$, followed by gram-positive CM and other CM. In addition, in the low permanent milk yield potential category, pregnant cows had a higher average cost of CM compared with open cows, but this was reversed in the average and high permanent milk yield potential categories. Similar to the trend at 4 mo after calving, younger cows had a higher average cost of CM than older cows, and the higher the permanent milk yield potential of the cow, the greater the average cost of CM (Table 5).

\section{Exit from the Herd (Voluntary and Involuntary Culling)}

When all different types of CM were included in the model, the percentage exit from the herd was $35.5 \%$ (17\% from voluntary culling and $18.5 \%$ from involuntary culling). This increased to $38.7 \%$ (20.8\% and $17.9 \%$ ) when milk price was increased by $20 \%$, and decreased to $33.1 \%$ (13.8\% and $19.3 \%)$ when milk price was reduced by $20 \%$. Herd exit decreased to $33.6 \%(14.4 \%$ and $19.2 \%)$ when replacement cost was increased by $20 \%$, and herd exit increased to $39.3 \%$ (17.5\% and $21.8 \%$ ) when replacement cost was reduced by $20 \%$. When the incidences of CM were halved, herd exit decreased to $34.4 \%$ (15.7\% and $18.7 \%)$, and when pregnancy rate was increased by $20 \%$, it decreased to $33.4 \%(13.8 \%$ and $19.6 \%)$.

\section{DISCUSSION}

When a cow contracts mastitis, the dairy farmer needs to decide whether treatment is warranted, and if so, what treatment is most appropriate. Ideally, these decisions are made based on the organism causing mastitis. In determining how to treat a cow, one common way of grouping these organisms is to separate them into gram-positive and gram-negative. These 2 groups of organisms cause mastitis of different symptoms and severity, and this classification can form the basis of on-farm treatment protocols (Hertl et al., 2010). 
Table 5. Average costs (in US\$) of 3 types of clinical mastitis (CM) in cows with different levels (low, average, high) of permanent (genetically determined) milk yield potential 8 mo after calving, obtained by the insemination and replacement optimization model ${ }^{1}$

\begin{tabular}{|c|c|c|c|c|c|c|c|c|c|c|c|c|c|c|c|c|c|c|}
\hline \multirow[b]{2}{*}{ Lactation } & \multicolumn{18}{|c|}{ Permanent milk yield potential } \\
\hline & GP & GN & $\mathrm{O}$ & GP & GN & $\mathrm{O}$ & GP & GN & $\mathrm{O}$ & GP & GN & $\mathrm{O}$ & GP & GN & $\mathrm{O}$ & GP & GN & $\mathrm{O}$ \\
\hline 1 & 15 & 15 & 15 & 125 & 137 & 115 & 151 & 193 & 142 & 125 & 150 & 115 & 170 & 248 & 164 & 125 & 167 & 115 \\
\hline 6 & 0 & 0 & 0 & 0 & 0 & 0 & 46 & 46 & 46 & 0 & 0 & 0 & 125 & 153 & 95 & 115 & 161 & 87 \\
\hline
\end{tabular}

${ }^{1} \mathrm{GP}=$ gram-positive $\mathrm{CM}$; GN = gram-negative $\mathrm{CM}$; and $\mathrm{O}=$ other $\mathrm{CM}$.

The importance and reliance on classifications of mastitis has become prevalent in the literature. For example, a study conducted by Neeser et al. (2006) found that the amount of antimicrobial use was significantly reduced when on-farm culture systems were used. Most producers treated gram-positive mastitis with antibiotics, whereas treatment for gram-negative mastitis varied. They concluded that the reduction in antimicrobial use could lead to several advantages, such as decreases in discarded milk and antimicrobial residues in milk, and improved treatment outcome due to targeted treatment. From our study, we found that the average cost per case of gram-negative CM (\$211.03) was due mostly to milk loss, which is logical given that the milk loss was greatest for gram-negative CM out of the 3 types of CM (see also Schukken et al., 2009). For gram-positive CM, this cost was primarily due to the treatment cost, which is also intuitive, given that the treatment cost was greatest for gram-positive CM, of all 3 types of CM. Similarly, treatment cost contributed most to the average cost per case of other CM.

The average cost per case with all 3 types of CM in the model was $\$ 155.08$, which is lower than that found in the study by Bar et al. (2008a) for generic CM, where the average cost per case was $\$ 179$. This difference is due to several reasons: our model was more detailed in that generic mastitis was differentiated into types, and data in our study were updated from Bar et al. (2008a). In Bar et al. (2008a) the parameter values used in the model (e.g., risk, treatment cost, involuntary culling) were for generic CM and not groups of $\mathrm{CM}$, and we did not include a carryover state from the previous lactation. Unlike the generic CM case, if we were to include a carryover state, we would need to model all possible combinations of carryover effects (e.g., gram-positive $\mathrm{CM}$ in previous lactation, gram-negative $\mathrm{CM}$ in current lactation, or gram-positive CM in previous lactation, gram-positive CM in current lactation). This would cause the state-space of the model to grow considerably, increasing the time and computing capacity necessary to calculate an optimal solution. The inclusion of carryover effect is an area of future research.

Although a few studies have examined the cost of CM in dairy cows, none has quantified this cost at the individual cow level for 3 types of CM. The study that comes closest to examining such costs was conducted by Sørensen et al. (2010). In that study, the authors estimated the costs related to 5 pathogen-specific mastitis traits and unspecific mastitis using a stochastic simulation model (SimHerd IV). Costs ranged from $\$ 189.42$ to $\$ 724.64$ per case (converted on Aug. 20, 2010, from $€ 149$ and $€ 570$, respectively), and were greater for contagious pathogens compared with environmental pathogens.

In our study, we estimated not only the cost of different types of CM, but also the sensitivity of these costs from parameter changes. When we increased the milk price, the average cost per case of CM increased, as the milk losses associated with each type of CM had greater value. The reverse was seen when milk price was reduced. Again, as expected, the average cost of gram-negative CM was most sensitive to this change. The same pattern was observed when replacement cost was increased.

We increased and decreased treatment cost by $20 \%$ to account for differences across farms in, for example, the use of antibiotics and associated discarded milk. We found that, despite these changes, the order of the cost of CM from most costly to least costly did not change (i.e., gram-negative was always most expensive, followed by gram-positive, and then other CM).

Between the 2 scenarios of increasing pregnancy rate or halving the incidence of $\mathrm{CM}$, it was apparent that the former case led to a reduction in the average cost/case of $\mathrm{CM}$, indicating the benefits to farmers of focusing on improving their breeding programs. In interpreting the results of the model, we emphasize that the cost of $\mathrm{CM}$ calculated by the model should be interpreted as the 
lowest cost possible following the optimal insemination and culling policy, under stable prices, and in a steady state. The best insemination and culling policy assumes a constant number of cows on the farm and immediate availability of replacement heifers. As a result, if the incidence of CM is halved, fewer cows are culled because of CM. Because the number of cows is constant, when fewer cows are culled because of CM (hence, less need for young replacement heifers), the cows in the herd will be getting older on average, and these older cows will be more prone to other diseases. Decreased culling rate also means less intensive genetic improvement (as we assume each generation to be more genetically advanced than the current genetic average). Therefore, our results show a slight decrease in the marginal net return per reduction of CM incidence. In reality, the decreased model-related culling would be translated to inner expansion or better selection of replacement heifers. As such, the value calculated from our model slightly underestimates the cost of CM.

Figures 2 and 3 illustrate that cows with CM should be replaced earlier than cows without CM, and that cows with lower milk yield should be replaced earlier than cows with higher milk yield. From Figure 3, it can be seen that cows with gram-negative CM should be inseminated only once compared with cows having gram-positive and other $\mathrm{CM}$; this can be attributed to the greater milk loss from gram-negative CM (Schukken et al., 2009), making it less optimal economically to incur the cost of inseminating them from that one point onward. The cross-sectional views of the figures (Tables 4 and 5) quantified what one would expect in the average cost/case of CM, as permanent milk yield, age, type of CM, and pregnancy status vary. For example, as permanent milk yield potential increased from low to high, the average cost/case of CM increased. As expected, the older the cow is, the lower the average cost/case of CM, because an older cow has less lifespan remaining than a younger cow for the cow to succumb to the detrimental effects of disease (and for these to be translated into monetary losses). Gram-negative CM generated the highest cost, as has been the case so far. Generally, CM cases were more costly in open cows, as they have the added effect of reduced fertility (unlike pregnant cows, as they are already with calf). Among cows 8 mo after calving (Table 5) in the low permanent milk yield potential category, however, pregnant cows had a higher average cost of CM compared with open cows, because these cows were further into pregnancy and had a greater probability of going to term (unlike cows at $4 \mathrm{mo}$, where the opposite trend was seen in average cost/case of CM).

As anticipated, when milk price increased, culling (voluntary) increased, due to the increased cost from milk loss and the greater expected profit of a replacement heifer. When the incidence of CM was halved and the pregnancy rate increased, culling (voluntary) percentages decreased. When replacement cost increased, culling (voluntary) was reduced, as it was more expensive to replace than to keep a cow.

In our model, we use a monthly time step, where we assume that, for example, all CM cases occurring 152 to $183 \mathrm{~d}$ after calving occur at d 183, enabling the decision to cull (and not treat) before incurring the costs of disease. The only exception to this is the first stage after calving, which has a length of only $3 \mathrm{~d}$; that is, we assume that all cows that have mastitis shortly after calving have it by d 3 after calving (Bar et al., 2008a). This is also because we estimate a greater risk for CM in this period.

Our study focuses on decisions for individual animals, and as such is an individual-based model. All modeling techniques have their advantages, which need to be weighed with their disadvantages in selecting the technique most appropriate for the study. The limitations of our individual cow model are that we cannot include herd dynamics (e.g., infectivity of CM) and see the effects of this at the individual cow level. If the latter were the focus of our study, then another modeling technique would be appropriate.

Our research was specific to cow characteristics, which allowed us to undertake a comprehensive analysis of the costs of CM by type. Further, the cost of disease depends on the fate of the cow. If the cow is to be culled, milk loss effects and fertility effects are not applicable. If the cow is pregnant, disease effects on fertility are not applicable. The model almost always recommended that pregnant cows be kept in the herd until the next lactation. Because the CM losses in these cows include only treatment cost and milk loss, and these were assumed to be the same for high- and low-yielding cows, the cost of $\mathrm{CM}$ is the same for all pregnant cows. Intuitively, one would assume that a high-producing cow loses more milk to $\mathrm{CM}$ compared with an average or low producer; however, we assumed the milk loss to be the same. Although we know that high milk production is a risk factor for mastitis (Gröhn et al., 1990, 1995), we have not investigated whether these losses are different for low- or high-yielding cows, although this would not be unexpected. Because we did not include this risk factor in our model and we assumed that milk loss was consistent across all milk production levels, more variability may exist in the results than currently shown in our model.

Furthermore, we did not model seasonality and milk component variations or the exact shape of the lactation curves beyond $10 \mathrm{mo}$, as these issues were beyond the scope of our study objectives. A further limitation 
includes the assumption that the farmer has complete knowledge of cow traits, and that a replacement heifer immediately enters the milking herd following a cow replacement, which is not always the case (Bar et al., 2008a).

The decision to treat that our economic model can recommend does not take into account how effective the treatment is. Given that in our current model, CM is divided into 3 categories of gram-positive, gramnegative, and other CM, the treatment policies for each type of bacteria in each category are assumed to be the same. Admittedly, the success and type of treatment for bacteria within each group, or even the same bacterial species between different strains, can differ; however, the focus of our economic model was not to assess the success of different types of treatment options.

This model, therefore, serves as a decision tool to aid farmers when deciding what to do with their diseased cows. The economic values, production costs, and disease frequencies can be altered; hence, the results can be made applicable to individual farms, although the values used here are representative.

\section{ACKNOWLEDGMENTS}

The USDA (CSREES) Award No. 2010-65119-20478 provided funding for this study. The authors thank the owners and personnel from the 7 dairies and the personnel of the Ithaca, Canton, and Geneseo Regional Laboratories of Quality Milk Production Services (Ithaca, NY) for their valuable cooperation.

\section{REFERENCES}

Bannerman, D. D. 2009. Pathogen-dependent induction of cytokines and other soluble inflammatory mediators during intramammary infection of dairy cows. J. Anim. Sci. 87(13 Suppl.):10-25.

Bar, D. 2007. Cost of generic clinical mastitis in dairy cows. PhD Thesis. Cornell University, Ithaca, NY.

Bar, D., L. W. Tauer, G. Bennett, R. N. González, J. A. Hertl, Y. H. Schukken, H. F. Schulte, F. L. Welcome, and Y. T. Gröhn. 2008a. The cost of generic clinical mastitis in dairy cows as estimated using dynamic programming. J. Dairy Sci. 91:2205-2214.

Bar, D., L. W. Tauer, G. Bennett, R. N. González, J. A. Hertl, H. F. Schulte, Y. H. Schukken, F. L. Welcome, and Y. T. Gröhn. 2008b. Use of a dynamic programming model to estimate the value of clinical mastitis treatment and prevention options utilized by dairy producers. Agric. Syst. 99:6-12.

Cha, E., J. A. Hertl, D. Bar, and Y. T. Gröhn. 2010. The cost of different types of lameness in dairy cows calculated by dynamic programming. Prev. Vet. Med. 97:1-8.

De Vries, A. 2006. Economic value of pregnancy in dairy cattle. J. Dairy Sci. 89:3876-3885.
Erskine, R. J., S. Wagner, and F. J. DeGraves. 2003. Mastitis therapy and pharmacology. Vet. Clin. North Am. Food Anim. Pract. 19:109-138.

Federal Reserve Bank of Kansas City. 2011. Agricultural Credit Survey: Interest Rate Data-Agricultural Interest Rates: Operating Loans, Federal Reserve Bank of Kansas City-Tenth Federal Reserve District, Quarterly Agricultural Credit Survey. Accessed Jan. 23, 2011. http://www.kansascityfed.org/research/indicatorsdata/ agcredit/.

Gröhn, Y. T., S. W. Eicker, and J. A. Hertl. 1995. The association between previous 305-day milk yield and disease in New York State dairy cows. J. Dairy Sci. 78:1693-1702.

Gröhn, Y. T., H. N. Erb, C. E. McCulloch, and H. S. Saloniemi. 1990. Epidemiology of mammary gland disorders in multiparous Finnish Ayrshire cows. Prev. Vet. Med. 8:241-252.

Gröhn, Y. T., R. N. González, D. J. Wilson, J. A. Hertl, G. Bennett, H. Schulte, and Y. H. Schukken. 2005. Effect of pathogen-specific clinical mastitis on herd life in two New York State dairy herds. Prev. Vet. Med. 71:105-125.

Gröhn, Y. T., D. J. Wilson, R. N. González, J. A. Hertl, H. Schulte, G. Bennett, and Y. H. Schukken. 2004. Effect of pathogen-specific clinical mastitis on milk yield in dairy cows. J. Dairy Sci. $87: 3358-3374$

Hertl, J. A., Y. T. Gröhn, J. D. G. Leach, D. Bar, G. J. Bennett, R. N. González, B. J. Rauch, F. L. Welcome, L. W. Tauer, and Y. H. Schukken. 2010. Effects of clinical mastitis caused by grampositive and gram-negative bacteria and other organisms on the probability of conception in New York State Holstein dairy cows. J. Dairy Sci. 93:1551-1560.

Kristensen, A. R. 1988. Hierarchic Markov processes and their applications in replacement models. Eur. J. Oper. Res. 35:207-215.

Kristensen, A. R. 1991. Maximization of net revenue per unit of physical output in Markov decision processes. Eur. Rev. Agric. Econ. 18:231-244.

Kristensen, A. R. 1996. Textbook notes of herd management: Dynamic Programming and Markov Decision Processes. Dina Notat No. 49, Dept. of Animal Science and Animal Health, Royal Veterinary and Agricultural University, Copenhagen, Denmark.

Kristensen, A. R. 2003. A general software system for Markov decision processes in herd management applications. Comput. Electron. Agric. 38:199-215.

Neeser, N. L., W. D. Hueston, S. M. Godden, and R. F. Bey. 2006 Evaluation of the use of an on-farm system for bacteriologic culture of milk from cows with low-grade mastitis. J. Am. Vet. Med. Assoc. 228:254-260.

Schukken, Y. H., J. Hertl, D. Bar, G. J. Bennett, R. N. González, B. J. Rauch, C. Santisteban, H. F. Schulte, L. Tauer, F. L. Welcome, and Y. T. Gröhn. 2009. Effects of repeated gram-positive and gram-negative clinical mastitis episodes on milk yield loss in Holstein dairy cows. J. Dairy Sci. 92:3091-3105.

Sørensen, L. P., T. Mark, M. K. Sørensen, and S. Østergaard. 2010. Economic values and expected effect of selection index for pathogen-specific mastitis under Danish conditions. J. Dairy Sci. 93:358-369.

Waage, S., P. Jonsson, and A. Franklin. 1994. Evaluation of a cow-side test for detection of gram-negative bacteria in milk from cows with mastitis. Acta Vet. Scand. 35:207-212.

Yazdankhah, S. P., H. Sørum, H. J. S. Larsen, and G. Gogstad. 2001. Rapid method for detection of gram-positive and -negative bacteria in milk from cows with moderate or severe clinical mastitis. J. Clin. Microbiol. 39:3228-3233. 